\title{
Languages, language-games, and forms of life
}

\section{Daniel Whiting}

The definitive version of this paper is to appear in The Blackwell Companion to Wittgenstein, ed. H-J. Glock and J. Hyman (Oxford: Wiley-Blackwell, Forthcoming). Please refer to the published version.

\section{$1 \quad$ Introduction}

A cursory glance at Wittgenstein's work, early and late, reveals a preoccupation with language, both as a source of philosophical puzzlement concerning concepts like time, knowledge, causation, and value, and as a phenomenon which is itself puzzling in various respects. One of the key innovations in Wittgenstein's later philosophy is the introduction of language-games. As I shall explain, Wittgenstein appeals to language-games in an effort to dispel the kinds of puzzlement just mentioned, as well as to illuminate language itself.

In comparison to talk of language-games, Wittgenstein talks of forms of life infrequently. Nonetheless, he is clear that the significance of the former lies in large part in its connection to the latter (PI §23). ${ }^{1}$ In what follows, I shall explain this connection. Having done so, I shall consider to what extent the view which emerges from Wittgenstein's remarks on language-games overlaps with a prominent view in contemporary philosophy of language.

\section{Objects of comparison}

In the first instance, Wittgenstein uses the phrase 'language-game' to refer to a (fictional) 'complete primitive language' (PI §2), which one could also view 'as one of those games by

\footnotetext{
${ }^{1}$ I use the standard references to Wittgenstein's texts throughout.
} 
means of which children learn their native language' (PI §7). Reflection on language-games, so conceived, is supposed to serve a therapeutic purpose: 'It disperses the fog' (PI §5). To appreciate this, consider the so-called 'Augustinian picture':

The words in language name objects - sentences are combinations of such names.- In this picture of language we find the roots of the following idea: Every word has a meaning. This meaning is correlated with the word. It is the object for which the word stands. (PI 1$)$

A picture like this, Wittgenstein suggests, feeds various forms of philosophical puzzlement. Consider:

(1) Elliot is larger than Stanley.

(2) Seven is larger than five.

(1) contains proper names, 'Elliot' and 'Stanley', which refer to individuals, in this case persons, which one might bump into, say, if one were in Southampton. It is natural to think that knowing what those words signify in some sense involves knowing those individuals, knowledge one might acquire by meeting them.

(2) is superficially similar in form to (1) - they share a 'surface grammar' (cf. PI §664). Accordingly, one might think that 'seven' and 'five' are also names which refer to individuals, presumably numbers. Might one bump into those individuals? Presumably not. Where, then, are they to be found, if not in Southampton? And how can one know what the names signify, if not by meeting their bearers? One soon finds oneself in deep philosophical waters. (I haven't even touched upon ‘is larger than’!)

Needless to say, this is a toy example-I am not suggesting anyone has fallen into confusion in such a simple-minded fashion—but it suffices for present purposes.

After sketching the Augustinian picture, Wittgenstein introduces his notorious builders: 
A is building with building stones: there are blocks, pillars, slabs and beams. B has to pass him the stones and to do so in the order in which A needs them. For this purpose they make use of a language consisting of the words "block", "pillar", "slab", "beam". A calls them out; B brings the stone which he has learnt to bring at such-and-such a call. (PI §2)

This language, Wittgenstein says, could be taught 'demonstratively'. The teacher directs the child's attention to a certain sort of stone, perhaps by pointing, and pronounces a word. Later, the teacher says a word and the child is rewarded if she brings one sort of stone, punished otherwise (cf. $B B$ 77).

Wittgenstein invites us to consider 'an extension' of the game:

The builder's man knows by heart the series of words from one to ten. On being given the order, "Five slabs!", he goes to where the slabs are kept, says the words from one to five, takes up a slab for each word, and carries them to the builder. (BB 79; cf. PI §8)

The builders use the numerals exclusively for counting. Significantly, the teaching of this game would be different. A child must memorise 'the series of number words' (PI §9). And, where the teaching is demonstrative, 'the same word, e.g., "three", will be taught by pointing either to slabs, or to bricks, or to columns, etc.' (BB 79).

These language-games are supposed to help us see how very different the functioning of count nouns, like 'pillar', is from the functioning of numerals, like 'five', differences the Augustinian picture slurs over. This might help us steer clear of the waters broached above. In the extended language-game, there is little temptation to speculate about what entities the numerals are correlated with and so where they might be found, or to worry about what kind of contact one would have to have with such entities in order to play the game. 
Wittgenstein is not denying that numerals signify or stand for numbers: 'we see no reason why we shouldn't speak of names of numbers' ( $B B$ 82). He asks only, 'How is what they signify supposed to come out other than in the kind of use they have?' (PI §10) The point of the language-games is to bring into view, beneath the surface level at which one talks of various words signifying or meaning various things, 'how fundamentally different the functions of such words are' ( $B B$ 82). What it is for 'five' to name a number differs from what it is for 'slab' to name a kind of stone - the underlying patterns of use which license the similar semantic descriptions are in each case dissimilar. In Wittgenstein's words, 'there is no one relation of name to object, but as many as there are uses of sounds or scribbles which we call names' (BB 173).

Admittedly, the remedy just outlined is as crude as the corresponding confusion. But it serves to illustrate one of the purposes Wittgenstein's descriptions of language-games are supposed to serve. (Wittgenstein puts them to more critical uses too, which there is not space here to discuss (see, e.g., PI §293).)

Clearly, a language like English is quite unlike the builders' 'system of communication'. For Wittgenstein, language-games serve 'as objects of comparison which, through similarities and dissimilarities, are meant to throw light on features of our language' (PI §130). Our 'everyday language', he says, is 'highly complicated' in ways which make it hard to survey and (so) apt to cause confusion. In contrast, language-games are 'clear-cut and transparent', though 'we recognize in these simple processes forms of language not separated by a break from our more complicated ones' ( $B B$ 17; cf. VoW 67). Returning to the example:

By introducing numerals we have introduced an entirely different kind of instrument into our language. The difference of kind is so much more obvious when we contemplate such a simple example than when we look at our ordinary language with innumerable kinds of words all looking more or less alike. (BB 79; cf. PI §335) 
In a similar fashion, Wittgenstein investigates language-games involving numerous other kinds of expressions, including demonstratives, colour words, epistemic terms, and aesthetic vocabulary.

\section{Language as a (collection of) game(s)}

Alongside his use of language-games as objects of comparison, Wittgenstein presents natural languages like English as language-games, or as consisting in such games. Recall his talk of 'the everyday language-games', quoted above (cf. PI §224), and his claim that 'our' language is 'not separated by a break' from the primitive activities. Elsewhere, he speaks of 'the' (actual) language-games involving terms like ‘describe' ( $P I \S 290)$, 'know' (OC §3), and 'looks' $(Z \S 422)$, and refers to activities like 'forming and testing a hypothesis', 'reporting an event', and 'describing an object by its appearance, or by its measurements' as languagegames (PI §23). At one point, he mentions 'the human language-game' (OC §554).

These remarks point to a picture of language as involving practices of employing expressions in certain ways, practices governed - following the game analogy—by rules, which determine the correct use of those expressions and by appeal to which participants regulate and evaluate their actions. In Wittgenstein's words: 'Following according to the rule is FUNDAMENTAL to our language-game' (RFM VI §28; cf. $V o W$ 87). On this picture, expressions mean (and name) what they do in virtue of the rule-governed role they play in the relevant language-game(s) (cf. BB 67; PI §43; RFM VI §41). As Wittgenstein says, 'A meaning of a word is a kind of employment of it [...] That is why there exists a correspondence between the concepts "rule" and "meaning"” (OC §§61-62). Elsewhere: "The meaning of a word is constituted by the rules for its employment' (VoW 143). In this respect, a language-game is a 'mode of representation' ( $P I \S 50)$. 
Wittgenstein insists on viewing language-games as 'complete in themselves, as complete systems of communication' ( $B B$ 81). This might encourage the following idea, which Wright captures (without endorsing): 'Each is self-regulating and answerable only to standards within it' (1992: 202). This is fine, if it means that the conditions for the correct use of an expression are determined only by the rules of the relevant language-game, which are conventional and arbitrary $(P I \S \S 355,497 ; P R \S 4)$. But it is mistaken, if it means that whether those conditions are satisfied on a given occasion of use is determined only by what is going on in the game, by its rules or by the other linguistic moves its participants make, as opposed to language-(game-)independent reality. The rules of the language-game settle what counts as correctly using 'red', for example, by including the principle that 'red' be applied only to this (pointing to a sample of red) (cf. PI §50). But whether one accords with this principle on a given occasion, and so correctly uses 'red', depends on whether one applies it to an object which is, in fact, red. As Wittgenstein remarks, 'If I say falsely that something is red, then all the same, it is red that it isn't' (PI \$429).

Above, I indicated how reflection on language-games is supposed to address specific forms of puzzlement. Wittgenstein's presentation of language as a rule-governed activity might address puzzlement concerning language itself, of a sort Horwich describes:

What is meaning? Why are some sounds imbued with it and others not? How, for example, does it come about that the word 'dog' means precisely what it does? How is it possible for those intrinsically inert ink-marks $[\ldots]$ to reach out into the world and latch on to a definite portion of reality: namely, the dogs? (1998: 1)

The idea that language is a game, and that uses of expressions are moves in it, might provide the beginnings of an answer to such questions: 'Every sign by itself seems dead. What gives it life?-In use it lives' (PI $\$ 432$; cf. BB 4). 


\section{(Forms of) life(-forms)}

Does presenting language as a game address the worries about 'dead' signs? After all, there are many activities in which tokens are moved subject to rules but in which those tokens do not possess meaning, and (so) cannot be used to say things, including, of course, games (cf. Lycan 2000: 81-82). Chess is not a 'mode of representation'!

Anticipating this, Wittgenstein suggests viewing language-games as embedded in non-linguistic activities:

If there were peoples whose troops moved in battle according to the same laws as the pieces on the chessboard, then a position of chess pieces would acquire a meaning at once, and the officers would then bend over the chessboard just as they would now over strategic maps [...] The movements of the pieces would simply be a representation of events in reality and not a 'mere game'. (VoW 149-150)

It is important to stress that Wittgenstein does not mention circumstances of significant activity into which language-games are woven only to address the 'mere game' objectionhis remarks highlight a feature of language-games, their embeddedness in larger contexts, already present. Such contexts are not supplementary to language-games but integral to them. From the outset, Wittgenstein presents each language-game as a 'whole, consisting of language and the activities into which it is woven' (PI §7). Again: 'The word "languagegame" is used here to emphasize the fact that the speaking of language is part of an activity, or of a form of life' (PI $\S 23)$. Thus, 'To imagine a language is to imagine a form of life' (PI $\S 19)$.

Following Cavell (1989), one can distinguish 'vertical' and 'horizontal' senses of 'form of life'. The vertical, broadly-speaking biological, sense concerns the life-form which 
each of us shares, the human organism, with all its physiological peculiarities. Our use of colour terms, for example, is bound up with, and so depends upon, the fact that we are endowed with a specific visual apparatus:

Imagine a tribe of colour-blind people, and there could easily be one. They would not have the same colour concepts as we do. For even assuming they speak, e.g. English, and thus have all the English colour words, they would still use them differently than we do and would learn their use differently. $(R C \mathrm{I} \S 13)$

Similarly, that we play certain language-games is dependent on certain 'very general facts of nature' ( $P P F \S 365$; cf. $O C \S 63 ; Z \S \S 351-352$ ). To adapt one of Wittgenstein's examples (PI $\S 142$ ), our terms of measurement might not have application were objects to expand and contract randomly.

The horizontal, broadly-speaking social, sense concerns ways of life, which humans might or might not share (cf. RFM VI §34). In Wittgenstein's view, 'What belongs to a language-game is a whole culture' ( $L C$ I §26). It is difficult to give uncontroversial examples of terms the use of which is bound up with, and so depends upon, habits and customs which reflect the outlook of a certain group; but consider how the practices involving 'chivalrous' are caught up in ways difficult to spell out with certain socio-historical circumstances, which have now passed, and certain values and principles, which are now foreign to us.

In a still more difficult to pin down fashion, language-game reflect their participants' sense for what is (not) important. Wittgenstein writes, 'We could say that people's concepts show what matters to them and what doesn't' ( $R C$ III §293; cf. $Z$ §378). For example, that we have a word with which to distinguish unmarried from married adult males but not one with which to distinguish married males with black hair over the age of eleven from anything else might indicate our sense of what needs noting. Someone with no sensitivity whatsoever to the 
significance of marital status - to the purposes of classifying people in this way — might be unable to participate in language-games involving expressions like 'bachelor'. As

Wittgenstein remarks, 'The game, one would like to say, has not only rules but also a point' (PI §564; cf. §570).

If language-games, hence languages, depend upon a form of life's horizontal and vertical dimensions, then where these dimensions vary the language-games, hence languages, might vary. Accordingly, Wittgenstein claims, 'an education quite different from ours might also be the foundation of quite different concepts' $(Z$ §387). Elsewhere: 'An entirely different game is played in different ages' ( $L C$ I $§ 25)$. And, as Wittgenstein explains, 'When languagegames change, then there is a change in concepts, and with the concepts the meanings of the words change' $(O C \S 65)$.

Does viewing language-games as embedded in non-linguistic activities, integrated vertically and horizontally within a form of life, speak to the worry that, on Wittgenstein's view, language might turn out to be a 'mere game', not a 'mode of representation'? To answer this, one would have to look at actual descriptions of rule-governed patterns of behaviour involving signs woven into wider contexts to ascertain whether they warrant semantic descriptions. Some doubt that the calls of Wittgenstein's builders qualify as language-use, properly so-called (e.g. Brandom 2008: 42; Rhees 1959-1960); be that as it may, there might be language-games which do so qualify.

\section{Context(ualism)}

I have outlined several respects in which, for Wittgenstein, language-games are inextricably bound to wider contexts - they are peculiar to environments, natural and social, tied to purposive activities, and play certain roles in, or for, the forms of life their participants 
inhabit. Does Wittgenstein advance any further ideas regarding the circumstances surrounding language-use?

It is increasingly common to interpret Wittgenstein's remarks on language-games as pointing to an influential position in contemporary philosophy of language: contextualism. 'Contextualism' is an umbrella term for numerous views - for present purposes, I shall restrict my attention to one. According to it, the use of the very same sentence (with whatever invariant meaning it bears in a language) might in different circumstances of use (literally) express any of an indefinite range of different propositions or thoughts with different truthconditions - not due to expressions which are uncontroversially indexical, like 'this', 'you', or 'now'. At the level of words: the same word (with the same meaning) might on different occasions make a different contribution to the proposition expressed by uses of sentences involving it.

To bring this down to earth, consider:

(3) Holly is tall.

Suppose that Holly is 6ft. By uttering (3), the contextualist claims, one might express a falsehood in one context—-say, when selecting a basketball team — and a truth in anothersay, when deciding what clothes to buy Holly-even though the words (and, in one sense, their meanings) remain the same, as does Holly's height. Insofar as there is nothing special about (3), the lesson generalises.

Conant and Travis are among the most influential proponents of a contextualist reading of Wittgenstein, although there are numerous others (see Whiting 2010 for references). According to Travis, Wittgenstein presents a 'new view' of language:

[Words'] semantics as part of their language, e.g. English, is at most a proper part of their semantics on an occasion of expressing a thought, and underdetermines what thought they would thus express, the latter varying while they mean what they do and have whatever 
semantics that confers on them. Their fixed, language-contributed semantics must, in general, be supplemented if they are to be properly assessable as to truth, that is, if they are to count either as true or as false [...] The role of a sentence, on this view, is not to be the expresser, in its language, of such and such thought, but rather to be usable on many different occasions for expressing any of many thoughts, each with its own condition for truth. (1991: 242)

In strikingly similar terms, Conant writes:

Wittgenstein thinks that it is a misunderstanding of how language works to think [...] that the role of a sentence in our language is to be that which on its own bat allows for the expression of a determinate thought - a determinacy which is achieved simply as a function of (1) the meanings of the individual words and (2) the rules of the language. The role of a sentence is to provide a linguistic instrument which is usable in many different circumstances to express any of many distinct thoughts $[\ldots]$ Each of these thoughts will be true under different conditions. (1998: 244)

On the picture developed in previous sections, what an expression means is determined by how it is be used according to the rules of the language-games involving it. Insofar as one might play such games on various occasions in various situations, the expression will bear the same meaning on those occasions in those situations. The contextualist claims that the meaning of an expression in this sense underdetermines the proposition expressed by the use of a sentence involving it on any given occasion. What is expressed by the use of an expression depends upon, not only the general principles for its employment, but the particular circumstances surrounding its employment. (A more radical contextualist might hold that there are no general rules for the use of an expression, only particular uses of that expression in particular situations.) 
Those who find contextualism in Wittgenstein often view his talk of language-games as primarily concerning, not rule-governed activities one might participate in on different occasions, but actual, concrete, embedded uses of language on specific occasions (cf. Conant, 1998: 233). In this manner, Travis writes:

The point of the discussion of language games $[\ldots]$ is that naming, or referring $[\ldots]$ underdetermines conditions for correctness of wholes [i.e. sentences], notably, where relevant, conditions for their truth. Wholes with given referents, embedded in different language games, would be true under any of many very different sets of conditions. (2008: 254)

Appeal to 'context-shifting' examples like that involving (3) above is a common strategy in support of contextualism. But do Wittgenstein's writings justify attributing to him a commitment to the view? As explored above, it is undeniable that Wittgenstein saw connections between what is expressed in the use of language and circumstances of use. But, while I was once unhesitant in attributing contextualism to Wittgenstein (Whiting 2010), and while I remain sympathetic to it, I am no longer confident that his remarks point toward contextualism (as characterised above). ${ }^{2}$

\section{This is here}

In support of their exegetical claims, Conant and Travis cite:

If, for example, someone says that the sentence "This is here" (saying which he points to an object in front of him) makes sense to him, then he should ask himself in what special circumstances this sentence is actually used. There it does make sense. (PI §117)

\footnotetext{
${ }^{2}$ My confidence here was shaken by Bridges (2010). Voltolini (2010) also denies that Wittgenstein is a contextualist, though on the grounds that Wittgenstein is a deflationist about truth (cf. PI §136). In (Whiting, 2011), I argue that contextualism and deflationism are consistent.
} 
Wittgenstein discusses similar examples in other passages, which Conant and Travis also appeal to:

A philosopher says that he understands the sentence "I am here", that he means something by it, thinks something — even though he doesn't call to mind in the least how, on what occasions, this sentence is used. (PI §514)

I know that a sick man is lying here? Nonsense! I am sitting at his bedside, I am looking attentively into his face.--So I don't know, then, that there is a sick man lying here? Neither the question nor the assertion makes sense. Any more than the assertion "I am here", which I might yet use at any moment, if suitable occasion presents itself. (OC §10)

The words "I am here" have a meaning only in certain contexts, and not when I say them to someone who is sitting in front of me and sees me clearly, - and not because they are superfluous, but because their meaning is not determined by the situation, yet stands in need of such a determination. (OC $\$ 348)$

Note that the relevant sentences contain uncontroversially indexical expressions whose reference varies with context ('I', 'here', 'this'). While Conant and Travis are right to suppose that Wittgenstein's point is independent of this, they are wrong to suppose that he is advancing contextualism.

The point Wittgenstein explicitly makes is that the relevant sentence 'makes sense', i.e. expresses a proposition, only in 'special circumstances' or 'certain contexts'. But there is no suggestion that, in different circumstances in which the sentence makes sense, it would make different sense, i.e. express different propositions. Rather, the idea seems to be that one 
does not count as playing the language-game with (the English words) 'I am here' in just any old situation — for one's use of signs so to count the situation must be 'suitable'.

What makes a situation suitable? Wittgenstein says little about that here but recall the idea that language-games have a point. Whatever point employing 'I am here' might serveto help others to locate oneself, say—is not served, Wittgenstein seems to suggest, 'when I say them to someone who is sitting in front of me and sees me clearly'. Hence, whatever is going on in such a situation, it is not recognisable as one in which someone is playing the 'I am here' language-game. Contrast the following situation: I'm talking to a friend via the internet. Aware I travel, she asks where I am. I hold up a map to the camera, point to it, and say 'I am here'. This situation, presumably, is recognisable as one in which someone is playing the language-game with 'I am here'.

So, Wittgenstein is suggesting that context determines whether a language-game is being played - and so whether subjects are employing expressions subject to the rules of that game. He is not suggesting that context plays a further role, namely, determining which of many propositions the expressions subject to those rules express. Compare: the fact that not just any context in which subjects move pieces shaped like castles and horses around a chequered board counts as one in which subjects are playing chess does not entail that, in different contexts in which subjects count as playing chess, the pieces have a different significance (cf. PI $§ 200)$.

One might think that the final passage shows Wittgenstein to be a contextualist, since he claims there that the meaning of a sentence (in the sense of the proposition expressed) 'is determined by the situation', as opposed, perhaps, to the general rules governing its constituents. In turn, one might think that, on this view, a different situation might 'determine' that the same sentence has a different meaning (in the relevant sense). 
But the passage says nothing whatsoever about different situations determining different meanings; it speaks only of words having 'a' meaning 'in certain contexts'. The point, again, seems to be that 'the situation' 'determines' that the sentence bears a certain meaning insofar as whether one counts as playing the relevant language-game, and so as using that sentence with that meaning, depends upon the circumstances. If they are not appropriate, one is not playing that language-game, but some other language-game (with similar sign-designs) or none at all.

Note that it is no part of the reading presented here that, for Wittgenstein, a sentence might fail to express a proposition in a given situation because the meaning it has somehow clashes with that situation, 'because of an incompatibility between the Satz and the context of use' (Conant 1998: 223). Nor is it part of that reading that the rules governing the expressions the sentence contains somehow determine that they fail to express a proposition or bear a meaning in that context. The proposal is only that, for Wittgenstein, absenting a suitable context with suitable purposes being served, the use of a string of signs does not qualify as the use of words bearing certain meanings or expressing a certain proposition, and so as governed by certain rules, more simply, as the playing of a certain language-game.

\section{I know that that's a tree}

Consider again:

I know that a sick man is lying here? Nonsense! I am sitting at his bedside, I am looking attentively into his face.- - So I don't know, then, that there is a sick man lying here? Neither the question nor the assertion makes sense. $(O C \S 10)$

Wittgenstein explores similar examples in the following remarks, which Conant cites as evidence of contextualism: 
"I know that that's a tree." Why does it strike me as if I did not understand the sentence? though it is after all an extremely simple sentence of the most ordinary kind? It is as if I could not focus my mind on any meaning. Simply because I don't look for the focus where the meaning is. As soon as I think of an everyday use of the sentence instead of a philosophical one, its meaning becomes clear and ordinary. $(O C \S 347)$

"I know that that's a tree" is something a philosopher might say to demonstrate to himself or to someone else that he knows something that is not a mathematical or logical truth. Similarly, someone who was entertaining the idea that he was no use any more might keep repeating to himself "I can still do this and this and this". If such thoughts often possessed him one would not be surprised if he, apparently out of all context, spoke such a sentence out loud. (But here I have already sketched a background, a surrounding, for this remark, that is to say given it a context.) But if someone, in quite heterogeneous circumstances, called out with the most convincing mimicry: "Down with him!", one might say of these words (and their tone) that they were a pattern that does indeed have familiar applications, but that it was not even clear what language the man in question was speaking. I might make with my hand the movement I should make if I were holding a hand-saw and sawing through a plank; but would one have any right to call this movement sawing, out of all context? - (It might be something quite different!) $(O C \S 350)$

If someone says "I know that that's a tree" I may answer: "Yes, that is a sentence. An English sentence. And what is it supposed to be doing?" Suppose he replies: "I just wanted to remind myself that I know things like that?” (OC §352)

In these remarks, Wittgenstein makes a familiar point. If I am to count as playing the relevant language-game with a sentence like, 'I know that that's a tree', and so if it is to have the 
meaning that it does (as determined by the rules governing its parts), the 'background' or 'situation' must be appropriate, one in which the use of those words can be seen to be serving suitable purposes. Without such a context, the sentence lies 'outside its language-game' (OC §393).

Once again, there is no suggestion that context plays an additional role, namely, supplementing whatever meaning the expressions have in virtue of being subject to the general rules of the language-game and, thereby, determining which of many propositions is expressed in their use. For all that Wittgenstein says above, if the circumstances are such that I count in them as playing the ('familiar', 'everyday') language-game with 'I know that that's a tree', then I count (in that context) as expressing the proposition that I know that that's a tree, the proposition I would express by using that sentence in any context in which I count as playing that game.

Conant might complain that I skipped this overtly contextualist passage:

"I know that that's a tree"- - this may mean all sorts of things: I look at a plant that I take for a young beech and that someone else thinks is a black-currant. He says "that is a shrub"; I say it is a tree.-We see something in the mist which one of us takes for a man, and the other says "I know that that's a tree". Someone wants to test my eyes etc. etc.—etc. etc. Each time the 'that' which I declare to be a tree is of a different kind. (OC \$349)

Certainly Wittgenstein here recognises variation of what is expressed with circumstances. But, as the final sentence makes clear, the variation here is of a familiar kind, due to the presence of the indexical 'that', which picks out a tree 'of a different kind' in each context. This does not support attributing to Wittgenstein contextualism of a more radical sort.

In the midst of the above, Wittgenstein offers the following analogy: 
Isn't the question "Have these words a meaning?" similar to "Is that a tool?" asked as one produces, say, a hammer? I say "Yes, it's a hammer". But what if the thing that any of us would take for a hammer were somewhere else a missile, for example, or a conductor's baton? Now make the application yourself. $(O C \S 351)$

If Wittgenstein were driving at contextualism, one would expect him to develop the analogy as follows: The very same tool, a hammer, could in various contexts be (used as) a missile or a baton. But what he actually says is that something which one would 'take for' a hammer might instead be a missile or a baton, depending on 'the application'. Again, Wittgenstein's point is that whether one counts as using an expression with a certain meaning depends on the situation, including what point one's use of it could there be serving, which is not to say that the very same expression with whatever meaning it has in the language might, in different situations, in the service of different points, express any of many propositions.

\section{A rose is red in the dark}

I have suggested that, in attributing contextualism to Wittgenstein, Conant and Travis are going beyond what is to be found in his remarks. Not only is this a misreading-it prevents us from appreciating the point Wittgenstein is actually trying to make. Consider the concluding sentence of $P I \S 514$, quoted above:

And if I say "A rose is red in the dark too", you virtually see this red in the dark before you.

\section{Wittgenstein continues:}

Two pictures of a rose in the dark. One is quite black; for the rose is not visible. In the other, it is painted in full detail and surrounded by black. Is one of them right, the other wrong? 
Don't we talk of a white rose in the dark and of a red rose in the dark? And don't we nevertheless say that they can’t be distinguished in the dark? (PI §515)

Travis provides the following gloss:

Is 'The rose is red' true of a rose in the dark? On one picture of a rose's being red, yes; on another, no. Depending on their surroundings, those words, by what they literally say, might present us with either picture as that in terms of which they are to be evaluated. (1991: 241)

Travis presents Wittgenstein's 'two pictures' as capturing different propositions one might express ('depending on the surroundings') in uttering 'A rose is red'. But why should either picture, both of which involve black paint, be thought to capture what is expressed by Travis's sentence, which makes no mention of the dark? Note that Travis changes the example from 'A rose is red in the dark too' to 'A rose is red'. Wittgenstein's sentence, unlike Travis's, is one which one can readily imagine being put to what Wittgenstein would call a 'philosophical', as opposed to an 'everyday', use (OC §347; cf. PI §116). Indeed, the fact that the example immediately follows that of 'a philosopher' uttering 'I am here' suggests that this is precisely what we are to imagine.

To appreciate what is going on in the passages, consider the context (!) in which they appear ( $P I \S \S 511-517$; also $Z \S \S 245-254)$. Wittgenstein's concern is how someone (say, a philosopher) might 'discover that a sentence does not make sense', that 'something that at first sight looks like a sentence [...] is not one'. She might insist that the relevant string of signs $i s$ a sentence with a sense, since she 'can imagine something in connexion with it' ( $Z$ $\S \S 247-248$ ). In response, Wittgenstein compares imagining (or 'picturing') something with 'drawing' something (PI §512)—-he commonly employs this strategy of 'replacing [a] mental image by some outward object' ( $B B$ 5) - and entertains the proposal to 'set it up as a criterion 
of understanding that one $[\ldots]$ be able to represent the sense of a sentence by drawing it' $(Z$ $\S 245)$.

By way of illustration, Wittgenstein's interlocutor insists that she can 'imagine a fourdimensional cube' $(Z$ §249). Various drawings are offered to her as capturing what she imagines, and so what she understands by 'four-dimensional cube', including:

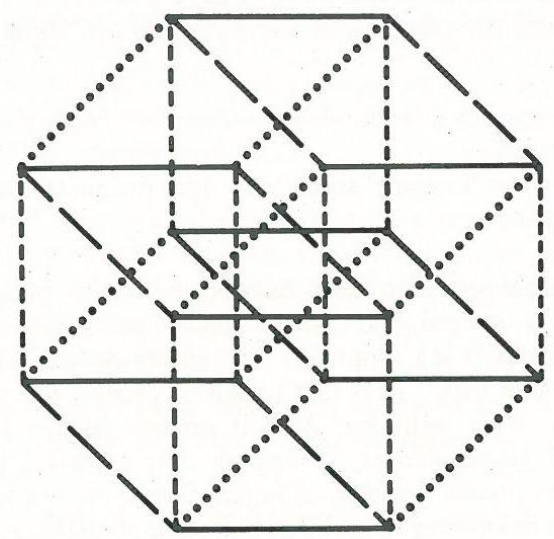

but none satisfies ('No; I don't mean that!'). Importantly, not only do the drawings fail to provide a sense for the relevant phrase, they seem to unsettle or undermine the interlocutor's conviction that she actually imagined something in connection with it: 'I have now for a picture only the words and my rejection of anything you can show me'.

That forming a mental image is neither necessary nor sufficient for using words with certain meanings is a well-worn point from Wittgenstein (cf. BB 4-5; PI §§139ff). The present point is more radical-Wittgenstein is exploring the possibility 'that we cannot imagine something which we believed we could imagine', which 'might lead us to revise what counts as the domain of the imaginable' (PI §517).

Returning in light of this to PI §§514-515, I suggest that Wittgenstein is concerned with someone (say, a philosopher) who thinks she grasps the sense of his sentence, 'A rose is red in the dark too', because she can imagine something in 'connexion' with it (she 'virtually see[s]' it). The two pictures are attempts to capture what she imagines, and so the sense of the sentence. Will the first picture do? Well, the rose seems missing from it. But, while a rose 
appears in the second, it no longer seems to be in darkness. Neither picture satisfies, and so neither provides a sense for Wittgenstein's sentence as it stands. By the same token, neither reveals what it is that the philosopher takes herself to imagine, which undermines the thought that there is anything which she imagines. Wittgenstein states the lesson as follows (note the scare-quotes):

Are roses red in the dark? - One can think of the rose in the dark as red.-

(That one can 'imagine' something does not mean that it makes sense to say it.) ( $Z$ \$250)

More positively, Wittgenstein recommends that we 'investigate [the sentence's] application in the language-game' ( $Z$ §247). Consider: I ask my infant son to hide the roses I've bought in the cupboard. He does so. To ensure there's a suitable array, I ask him how many red roses we've got. He replies, 'None - the lights are off'. Momentarily puzzled, I realise he doesn't quite grasp the logic of colour terms yet. By way of instruction, I say, 'A rose is red in the dark too'. It is in virtue of playing its role in such a context, not in virtue of what one (seems to) imagine, that the string of signs constitutes a sentence expressing a sense.

So, Wittgenstein's point, again, is that a suitable occasion involving suitable purposes is required if a sentence is to bear a certain meaning, and hence express a certain proposition, that is, if one is to count as playing a certain language-game. Nothing Wittgenstein says here points toward the idea that the same sentence, with whatever meaning it bears independently of an occasion of use, might express different propositions on different occasions. Moreover, and crucially, these passages are in addition addressing 'a lack of clarity about the role of imaginability in our investigation. Namely, about the extent to which it ensures that a sentence makes sense’ (PI §395). So, not only are Wittgenstein's remarks not in the service 
of promoting contextualism, thinking that they are prevents us from seeing the work they are supposed to be doing.

\section{Conclusion}

I outlined the methodological role which appeals to language-games play in Wittgenstein's philosophy, and indicated the picture of language which his discussion of such games and their relations to forms of life suggests. In doing so, I challenged the claim that those remarks point to a kind of contextualism widespread in contemporary philosophy. I should stress that I am not challenging contextualism itself. Nor am I denying that it in many ways accords with the spirit of Wittgenstein's philosophy. My claim is only that he does not advance it in the passages examined. Of course, this is a limited conclusion. There are other passages which scholars appeal to as evidence of contextualism in Wittgenstein's work (see Travis 2006), some of which Bridges examines (2011). But perhaps the fact that passages frequently cited as providing such evidence do not is reason to re-examine the significance of Wittgenstein's remarks on our language(-game) and its indissoluble connections to context. For Wittgenstein, the meaningful use of language involves rule-governed practices of employing expressions tied to provincial points and purposes, embedded in specific natural and social environments, bound up with, indeed manifesting, distinctive forms of life. Contextualism, of the sort explored here, might be more of a hindrance than a help when it comes to appreciating the importance Wittgenstein sees in this. ${ }^{3}$

\section{References}

Brandom. R. 2008: Between Saying and Doing. Oxford: Oxford University Press.

\footnotetext{
${ }^{3}$ Thanks to Jason Bridges, Denis McManus, Ray Monk, and Genia Schönbaumsfeld for feedback on earlier versions of this material.
} 
Bridges, J. 2010: Wittgenstein vs. Contextualism. Wittgenstein's Philosophical Investigations: A Critical Guide, ed. A. Ahmed. Cambridge: Cambridge University Press.

Cavell, S. 1989: This New yet Unapproachable America. Chicago: University of Chicago Press.

Conant, J. 1998: Wittgenstein on Meaning and Use. Philosophical Investigations 21: 222-250.

Horwich, P. 1998: Meaning. Oxford: Oxford University Press.

Lycan, W. 2000: Philosophy of Language, $2^{\text {nd }}$ ed. London: Routledge.

Rhees, R. 1959-1960: Wittgenstein's Builders. Proceedings of the Aristotelian Society 60: $171-186$.

Travis, C. 1991: Annals of Analysis. Mind 100: 237-264.

Travis, C. 2006: Thought's Footing. Oxford: Oxford University Press.

Travis, C. 2008: Occasion-Sensitivity. Oxford: Oxford University Press.

Voltolini, A. 2010: Is Wittgenstein a Contextualist? Essays in Philosophy 11: 150-167.

Whiting, D. 2010: Particular and General: Wittgenstein, Linguistic rules, and Context. The Later Wittgenstein on Language, ed. D. Whiting. Basingstoke: Palgrave.

Whiting, D. 2011: Leave Truth Alone: on Deflationism and Contextualism. European Journal of Philosophy 19: 607-624.

Wright, C. 1992: Truth and Objectivity. Cambridge, Massachusetts: Harvard University Press. 